\title{
CONSUMER ATTITUDES TOWARDS FASHION INFLUENCERS ON INSTAGRAM: IMPACT OF PERCEPTIONS AND ONLINE TRUST ON PURCHASE INTENTION
}

\author{
Joanna K. Santiago, Universidade de Lisboa-ISEG, joannas@iseg.ulisboa.pt \\ Daniel Magueta, Universidade de Aveiro, dmagueta@ua.pt \\ Cataria Dias, Universidade de Lisboa - ISEG, catarinavdias@ua.pt
}

\begin{abstract}
The growing importance of digital influencers has been already acknowledged both by companies and by the academy. However, due to its contemporaneity, the literature regarding this topic still faces some limitations. Thus, the present study intends to explore the antecedents of the trust in influencers and the consequent purchase intention. To develop their digital strategies, it is essential that companies understand consumers' attitudes towards digital influencers. Consequently, they have to identify the antecedents of trust in influencer as well as their consequences on purchase intention. The research objectives of this study are (1) to design a framework of the relationship between customer perceptions that will determine the trust, influencer trust and intention to buy, and (2) to test and validate this framework using a sample of Portuguese consumers. The research followed a quantitative approach with a nonprobabilistic convenience sampling. To achieve the objective of this research an online survey was conducted ( $n=242)$ among individuals who are following fashion influencers on Instagram. The results showed that purchase intention is indeed influenced by influencer trust and brand credibility is an important antecedent both to build the trust and purchase intention. This study allowed a better understanding of the role of fashion influencers in social media from the user perspective, allowing the enrichment of information in the Portuguese context. At the business level, this research has provided evidence that the use of digital influencers is a successful tool for marketers in the fashion segment.
\end{abstract}

Keywords: Digital Influencers, Influencer Marketing, Influencer Trust, Purchase Intention.

\section{INTRODUCTION}

Undeniably, with the advancement of information and communication technologies, the way the individual has access to information is immediate and easier. Given the significant evolution of the Internet, the means of delivering information and marketing strategies focused on salespeople are no longer effective (Lu, Chang \& Chang, 2014). Today's consumer trusts friends and family more than he trusts the companies while evaluating a product or service before making a purchase decision (Lee \& Koo, 2012).

Nowadays, companies consider online media to be a strategic communication tool. In addition, brands already recognize the power of influential members on these online platforms, that is, digital influencers who share experiences with brands on a daily basis (Uzunoglu \& Kip, 2014).

The phenomenon of influencers did not originate with the appearance of the Internet, they were already offline which is the case of influential people such as musicians, politicians or film artists who influenced people in their environment (Spry, Pappu \& Cornwell, 2009). What really brought the Internet up again was experienced influencers in the field and not just public figures who are associated with brands. These influencers are now named digital influencers (Marketeer, 2018). This boom of influencers began at a time when companies, as mentioned above, recognized them as a way of reaching more loyal and more involved audiences, thus enabling better segmentation and the ability to direct moments of communication to the intended target.

The fashion sector is one of those that has invested more in this communication strategy, getting more and more involved with Instagrammers, Youtubers and bloggers (Brandtellers, 2017). Nowadays, social networks play an essential role in the daily life of each individual, not only on a personal level but also on a social level. Through 
presence on social networks, such as Instagram and Facebook, it has become increasingly easy to share consumers' experiences and opinions with their friends and family, as well as to share the experiences of influencers (Sudha \& Sheena, 2017). Previous literature reveals a lack of understanding of the mechanisms by which influencer marketing content and influencers themselves affect consumer behavior. This study intends to fill this research gap. The main objective of this study is to analyze the customer perceptions of the opinion leaders in a specific social network, namely Instagram, and to understand how those perceptions affect purchase intent.

\section{BACKGROUND AND LITERATURE REVIEW}

There are four theories that we can indicate as important to the background of our study: the social identity theory, the theory of planned reason (reasoned action), the theory of planned behavior and the self-congruence theory. Social identity theory is an interactionist social psychological theory of the role of self-conception and associated cognitive processes and social beliefs in group processes and intergroup relations (Abrams \&Hogg). Hoonsopon and Puriwat (2016) in their study on effect of reference groups on purchase intention, contributed to social influence theory by revealing that indeed reference groups have a diverse impact on purchase intention under different stimuli. The authors stated that consumers use friends and family as private sources, and they use celebrities and influencers as public sources. Also, whereas identification with a group is claimed to be based on the desire for self-definition, identification with an individual is argued to be predicated on the desire to conciliate, imitate, or vicariously gain the qualities of the other (Kelman, 1961; Ashfort \& Mael, 1989). That could explain the success of influencers.

The theory of reasoned action and the theory of planned behavior also provide some underpinning conceptual frameworks for understanding the factors that affect influencer trust and purchase intention. Both of those theories assume that the best predictor of a behavior is the intention determined by attitude and social normative perceptions regarding it (Montano \& Kasprzyk, 2015). Trust has been measured as the most critical reason which encourages customers to purchase behavior and uncertainty avoidance is directly linked to multidimensional trust. A higher level of trust in influencer causes a more positive attitude and higher intention to purchase.

Finally, and probably the most essential for this study, the self-congruence theory which refers to "the likeliness of comparing oneself with other objects and stimuli" (Liu et al., 2012, p. 923). Self-congruity has been widely adopted in brand-related research to help both researchers and practitioners understand brand purchasing behavior. The basic premise in the self-congruity theory suggests that consumers prefer products or brands that balance with their selfperception and are likely to have favorable attitudes and purchase intention toward brands whose images are congruent with their self-images (Xu \& Pratt, 2018).

\section{Social Media and Influencer Marketing}

Social media are growing exponentially, with millions of people around the world creating and sharing new content (Asur et al., 2011). Social media are defined as the activities, participations and behaviors of people in online communities to share information, knowledge and opinions (Erdogmus \& Çiçek, 2012; Kim \& Ko, 2011). Correspondingly, social media marketing becomes an excellent vehicle for promoting an effective relationship with the customer (Vries, Gensler \& Leeflang, 2012). The effective use of social media marketing provides companies with a better communication environment that allows to create superior brand loyalty (Erdogmus \& Çiçek, 2012).

Influence marketing, or influencer marketing, according to Bro (2017) consists of individuals with a certain degree of influence over their target audience, thus promoting activities or product promotions around these influencers. Brands sponsor digital influencers to promote products to their followers so that they share their opinions and experiences in the digital medium.

In accordance to Sammis et al. (2016), the marketing of influence (influencer marketing) is defined as the art and science of involving influential people in the online world to share with followers their opinion on sponsoring brands. This trend in digital marketing has been superimposing on traditional marketing, which is based mainly on the use of television and radio, and which is more oriented towards the general market and does not act directly on its target audience. 
According to studies by Keller Fay Group (2016), the use of influencer marketing brings a large number of benefits to companies, also the impact that influencers have on consumers is increasing. Most of the consumers are very likely to follow the recommendations of a digital influencer.

A recent study on social media trends stated that $94 \%$ of marketers who have used influencer marketing campaigns found them effective (Ahmad, 2018). The same article also stated that influencer marketing produced 11 times the return on investment (ROI) of traditional advertising.

This success might be explained by the fact that through the digital medium it is possible to reach the specific target audience and establish a greater relationship between the brand and the consumer (Tarik \& Adnan, 2018). This way, through the influencer marketing it is possible to expand the audience and transform it in brand-loyal consumers, where trust and authenticity are emphasized (Sudha \& Sheena, 2017).

\section{Digital Influencers}

Undeniably, opinion leaders play an important role in the information dissemination process, many times leading to product acquisition. Opinion leaders are defined as individuals with great influence power on other people's attitudes and behaviors, as well as on their decision-making (Rogers \& Cartano, 1962). We can find the background evidence to sustain the importance of influencers as opinion leaders in the social identity theory.

Currently, an opinion leader does not only act offline, but also in the online environment, and is now being called a digital influencer. According to Pereira and Alturas (2018), a digital influencer is a person whose opinion is respected and applied in the purchase decision process. In accordance with Freberg et al. (2011, p. 90), an influencer is "a new type of third-party endorser that shapes the audience through blogs, tweets and the use of other social networks". In the same study, the authors define digital influencer as a person with a certain credibility in a given area. In addition, a true influencer should be a person with the ability to convey confidence to public (Rebate, 2017).

According to Casaló, Flavián and Ibáñez-Sanchez (2018), an opinion leader must have at least one of the following characteristics: be a specialist in relation to a particular product or service; be an active member in a social network; participate regularly in online community and/or be considered as a person who makes good decisions when buying a product or service.

Accordingly, digital influencers are online personalities able to influence their followers on various social media platforms (Lou \& Yuan, 2018). Contrary to celebrities or public figures who are well-known via traditional media, social media influencers become likeable by creating and posting content on social media.

Nowadays, it is becoming common for the brands to use digital influencers to promote their products. This might be explained by a few facts: 1) digital influencers tend to be more affordable than renowned celebrities; 2) influencers have already established themselves in certain areas, normally getting to some level of expertise, and most importantly, 3 ) they normally seem to be more believable in customers eyes and therefore they receive more trust (Lou \& Yung, 2018).

Consequently, digital influencer marketing refers to a form of marketing where marketers and brands invest in selected influencers to create and/or promote their branded content to both the influencers' own followers and to the brands' target consumers.

\section{Consumer Behavior}

Solomon (2009, p.6) defines consumer behavior as "the study of processes involved when individuals or groups select, buy or reject products, services, ideas or experiences to satisfy needs and desires". In agreement with Solomon, Chaturvedi and Barbar (2014) define customer behavior as the study of people, groups or organizations and the processes implied to select and discard products or services that meet their needs and wants. The theory of planned behavior helps to understandin the factors that affect purchase intention and assumes a causal chain that links behavioral beliefs to behavioral intentions and behaviors via attitudes (Montano \& Kasprzyk, 2008). 
In today's media landscape, mass communication channels are no longer the dominant sources of information for consumers. Instead, each time more, consumers use social media or virtual communities for information exchange (Lou \& Yuan, 2018).

According to Chaturvedi and Barbbar (2014), one of the main changes in consumer behavior, resulting from social networks, is that customers increasingly assume a pertinent position in the transmission of their knowledge and particular needs, and as a result they have a stronger voice today. Indeed, social networks have increasingly become a place for information sharing (Chaturvedi \& Barbar, 2014).

The proposed research model is detailed in Figure 1.

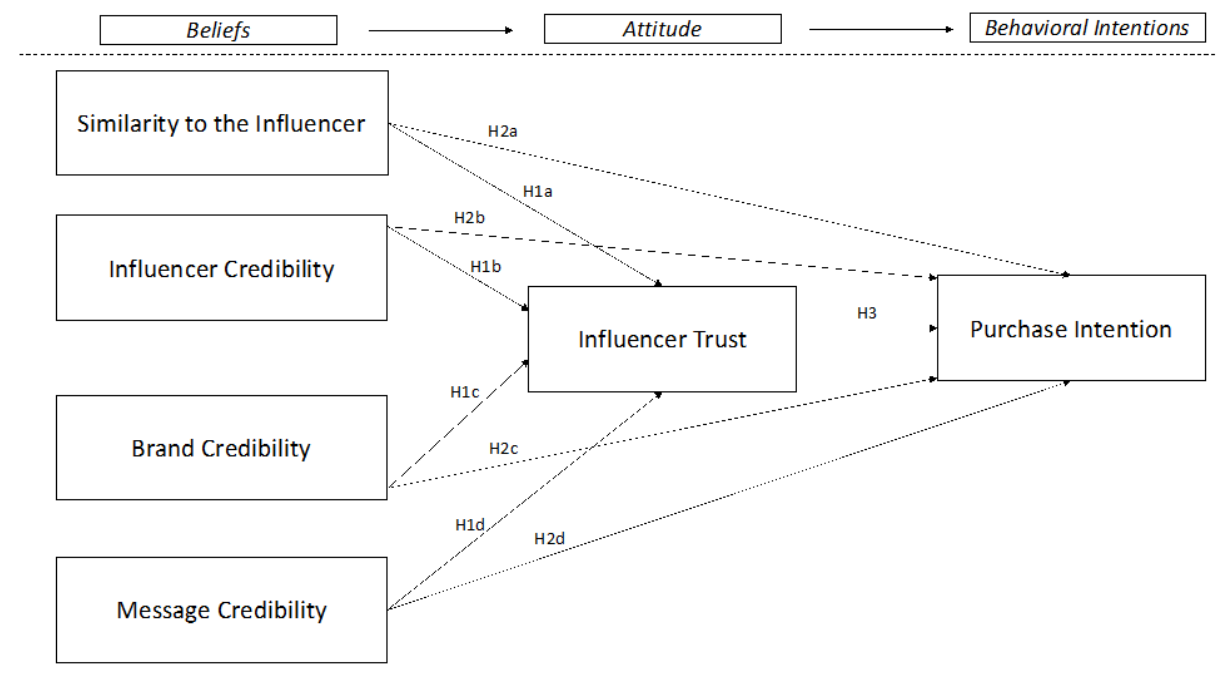

Figure 1. Proposed research model.

\section{Influencer Trust}

Influencer potential is largely affected by trust (Lindh \& Lisichkova, 2017). There are several ways to define trust, both online and offline. It can be said that trust is a psychological state of interaction between personal values, felt of humor and attitude. Moorman, Deshpande and Zaltman (1993) described trust as "a willingness to rely on an exchange partner in whom one has confidence" (p. 82).

In accordance to the theory of reasoned action, they are two components expected to influence behavioral intention: attitude (confidence and trust) and the subjective norm (influence) (Chuchinprakarn, 2005).

This study emphases influencer perceived trust which is related to online trust. Online trust slightly differs from offline trust (Bart et al., 2005). Unlike trust in real life, the object of online trust is the website, the Internet, or the technology itself (Hui-Yi \& Pi-Hsuan, 2010). It can be said that online trust is based on the interactions of individuals with the website (Bart et al., 2005). Similarly, the digital influencers perceived trust is based on the relations of individuals with the influencer.

Ho and Chien (2010) defined online trust as a form of relationship, that is, the trust that is issued to an individual in relation to a website. This online trust essentially includes individual perceptions of how credible the information provided by the website is and how trustworthy it is.

These perceptions in relation to the website are defined through several antecedents (Bart et al., 2005). In agreement with Bart et al. (2014) trust in a website, or any social network occurs through the interaction and evaluation of the site. 
As concerns influencer marketing Lou and Young (2018) argue that influencer marketing's content factor (such as the perceived informativeness value and entertainment value of influencer-generated post) affect consumers' trust in their advertised content (branded posts).

\section{Purchase Intention}

According to Spears and Singh (2004) and Lu et al. (2014), the purchase intention is seen as a conscious plan consumer to purchase a product. It can be said that the intention to purchase means the willingness of consumers to purchase a product at a specific time or in specific situation. According to Oke et al. (2016), there are four main factors that affect the consumer purchase intention. First, cultural factors such as core beliefs and values and the social class in which consumers are inserted. The purchase intention can vary from country to country, depending on various cultural factors that are prevalent in different regions of the globe. Then, social factors such as groups, family members, friends and opinion leaders, have a significant impact on the individual purchase decision. Third, the individual characteristics of the customer, that affect the personal motivations, perceptions and specific preferences. Last but not least importantly, the psychological factors that include motivation, attitudes, beliefs and individual perceptions.

\section{Similarity to the Influencer}

The resemblance of the recipient to the content creator can be measured by the way in which the individual believes that he is similar to the influencer, that is, that he has the same tastes and preferences (Esch et al., 2018). Consumers tend to relate to people essentially in terms of values, gender, education and lifestyle. In this case, when these ties are relatively strong, it means that the source and the receiver are very similar. Consequently, the similarity between individuals establishes higher levels of trust, understanding and attraction (Esch et al., 2018).

The similarities between an influencer and the consumer reflect the likelihood for the consumer to be influenced by the content created by the influencer. Therefore, the stronger the similarity between the two, the greater the probability that the consumer will be influenced by the content creator (Moon \& Han, 2011).

Today, as consumers are more sophisticated and informed, they create defenses in relation to more traditional advertising - they are suspicious and easily detect when they are being persuaded. Before purchasing a product, the consumer prefers first check with people similar to him, and this searched recommendation always involves trust and authenticity. The literature adds that consumers "more than then in companies, (...) believe in people" (Costa \& Alturas, 2018, p.2).

Basing on those assumptions, we propose the following hypotheses:

H1a: There is a relationship between the similarity to the influencer and the perceived trust related to the influencer. H2a: There is a relationship between the similarity to the influencer and the purchase intention.

\section{Influencer Credibility (Credibility of the Source)}

The credibility of the source boils down to the fact that the recipient of the message believes source of the information transmitted has knowledge, skills and experience on the subject. Above all, consumers believe that the message conveyed is objective and without prejudice (Ho \& Chien, 2010). Indeed, credibility and trust face a fundamental role in the dissemination of knowledge among human beings.

Lou and Yuan (2018) in their study on the effect that message value and source credibility have on customer trust of branded content on social media, have investigated endorsers' influence on consumers and focused directly on the fundamental mechanisms of what makes influencer marketing effective. The authors emphasized not only the roles that advertising content plays, but also the messenger particular features and used source credibility to gauge a source's influence on the effectiveness of persuasive messages.

Indeed, credibility of the source is induced in the information and content of the posts created by the influencers. Consumer confidence in opinion leaders is revealed when they are induced to share their own knowledge (Chai, Das \& Rao, 2011). Thus:

H1b: There is a relationship between the influencer credibility and the trust in influencer.

$\mathrm{H} 2 \mathrm{~b}$ : There is a relationship between the influencer credibility and purchase intention. 


\section{Brand Credibility}

Brand credibility, according to Esch et al. (2018), measures the communication veracity of a product or brand. The credibility of a brand's information depends extensively on what the influencers promise and what information they share with consumers (Esch et al., 2018). Effectively, the brand credibility relies on the quality of the information it transmits to consumers through its various marketing strategies and through its sponsored influencers (Spry et al., 2011).

The credibility conveyed by opinion leaders positively influences the audience's attitudes towards the ad and consequently towards the brand. In this way, it can be said that the brand credibility is made up of the credibility of information that allows the consumer to believe that the brand has the capacity to offer what was promised (Erdem $e t$ al., 2006). Also, more credible the brand, customer will expose more trust to the influencer who supports it. Furthermore, the greater the credibility of the brand, the greater the confidence that the consumer will have in the quality of the products that the brand offers, thus influencing the purchase intention (Spry et al., 2011). Therefore:

H1c: There is a relationship between the brand credibility and trust related to the influencer.

$\mathrm{H} 2 \mathrm{c}$ : There is a relationship between the brand credibility and purchase intention.

\section{Message Credibility}

The credibility of the message refers to the evaluation of the characteristics of the exposed information that will produce credibility (Cosenza et al., 2014). In accordance, the message credibility can be assessed in several aspects, such as the quality of information, plausibility, accuracy, use of evidence, language intensity and message discrepancy (Cosenza et al., 2014). Thus:

H1d: There is a relationship between the message credibility and trust related to the influencer.

$\mathrm{H} 2 \mathrm{~d}$ : There is a relationship between the message credibility and purchase intention.

\section{Influencer Trust and Purchase Intention}

Previous research has argued that trust (including cognitive, emotional, and behavioral dimensions), can bring a "willingness to act on ad-conveyed information" (Soh, Reid \& King 2009, p. 86). Morgan and Hunt (1994) posited that trust in a trade partner involves behavioral intentions to rely on that partner. Speaking in online terms, similarly as in the community offline, trust is designated as the main component for people to build relationships with each other, to share and receive information. Also, Ho and Chien (2010) argue that trust in the online world is defined as one of the most influential and positive factors in the users' decision share their knowledge as well as their involvement in electronic commerce. Trust is defined as a factor with great importance in the decision making of the consumers and the knowledge transaction in the online context (Chai \& Kim, 2010). Correspondingly, if consumers perceived a digital influencer as a trustful source, they also will be more likely to convey the purchase intention in relation to the product being recommended (Lu et al., 2014; Lou \& Young, 2018).

According to Esch et al. (2018), trust in an Instagrammer measures until point the consumer believes the opinion leader's word and considers his advice as honest and trustworthy. In this way, the consumer's purchase intention will increase (Esch et al., 2018).

Based on those premises, we suggest:

H3: There is a relationship between trust in influencer and purchase intention. 


\section{METHODOLOGY}

\section{Data Collection}

The research method used for the study was the survey by questionnaire $(n=374)$. The questionnaire was published online (on Qualtrics platform) and disseminated via messages sent through social networks like Facebook and Instagram and via email.

The social network under study, Instagram, appears in the context of web 2.0 and constitutes as a digital platform launched in 2010, which allows its users share photos and videos with other users through an application (Hu, Manikonda \& Kambhampati, 2014). This social network allows its users to share their daily life instantly with family and friends through the use of videos and photos (Hu et al., 2014). Instagram has been the platform where it is possible to verify a greater number of digital influencers. Thus, it is in this social network that we can observe a greater communication of brands through opinion leaders (Sammis et al., 2016). This social network has become popular as an instrument of influence marketing as this communication is done through photos or videos which help to absorb the information that is transmitted to the consumer.

\section{Measures}

This study used established scale items, consisting of such measures as: similarity to the influencer/source, brand credibility, purchase intention (Esch et al., 2018), source and message credibility and influencer trust (Cosenza et al., 2014). But first, two filter questions were applied to exclude individuals who are not users of Instagram, or who do not follow fashion influencers on Instagram.

\section{Data Processing}

The data processing was supported by IBM SPSS Statistics 24 . The total number of responses obtained through the questionnaire was 374 , but only 242 were considered valid for the study. In total, 132 responses were excluded because they did not belong to the population for the study in question or did not complete the questionnaire (Malhotra \& Briks, 2006). The filter questions posed in the questionnaire led to eliminate 14 individuals, who were not users of Instagram and 82 individuals who do not follow fashion influencers on Instagram. The remaining 32 respondents were excluded from the analysis because they did not complete the questionnaire.

\section{Sample Characterization}

The sample of the present investigation is constituted by 242 individuals who affirm to be followers of fashion influencers on Instagram. Of the total respondents, around $87.2 \%$ are female and $12.8 \%$ male. Most respondents are in the 18 to 23 age group (44.6\%) and between 24 and 29 years old (38.8\%). Then, regarding the marital status of the respondents, it is noted that the absolute majority is single (88\%). As it comes for the qualifications: $45.5 \%$ of respondents have graduated, followed by $20.2 \%$ who have Master's degree and $19 \%$ who have a secondary education degree. Regarding occupation, it appears that $45.5 \%$ are employees, $24.4 \%$ of respondents are students and about $19.8 \%$ are working students. With regard to the personal net monthly income, $38.4 \%$ of respondents say their income is between $500 €$ and $1000 €, 15.3 \%$ of respondents earn more than $1000 €$ and up to $1500 €$ and $7.4 \%$ of respondents have income that is lower or equal to $500 €$. All the respondents come from Portugal.

In order to carry out a more complete sample characterization, respondents were asked to indicate the average time that they use the social network per day and the reasons why they follow fashion influencers on Instagram. In this sense, it was found that $39.8 \%$ of respondents use the Instagram on average one to two hours a day, $25.8 \%$ of respondents use it between two and three hours per day, and 20.9\% of respondents access Instagram more than three hours daily. Finally, we can highlight that the main reason that respondents follow fashion influencers is to "get ideas and inspirations for what to wear on a daily basis or on special occasions" ( $71.1 \%$ answers), the second reason that leads them to follow influencers is to "obtain recommendations and fashion tips" (51.7\%), and another reason indicated was to "get to know news about new fashion articles on the market" (47.9\%). 


\section{RESULTS}

\section{Reliability and Internal Consistency Analysis}

In order to insure the data reliability, the Cronbach's alpha was tested for each scale (see Table 1). In each of the variables under study, it is recommended that they have a value of Cronbach's Alpha greater than 0.7 to be able to affirm a good reliability and internal consistency (Pallant, 2016). However, Taber (2018) defends that the value of Cronbach's Alpha is acceptable between 0.6 and 0.7. Considering the previous statements, two items could be excluded, namely: "I like the content that is shared on the profiles of the digital influencers", and, "I don't hesitate to buy an article advertised by an influencer". However, both items were not excluded as their exclusion would cause the loss of relevant data for the investigation, with the variables having only 3 items and the values are very close to 0.7 , their exclusion is not justified.

Table 1. Reliability and Internal Consistency Analysis

\begin{tabular}{|l|c|}
\hline Index & Cronbach's Alpha \\
\hline Similarity to the source & 0.834 \\
\hline Source credibility & 0.761 \\
\hline Brand credibility & 0.860 \\
\hline Message credibility & 0.654 \\
\hline Online trust & 0.834 \\
\hline Purchase intention & 0.687 \\
\hline Word of Mouth & 0.849 \\
\hline
\end{tabular}

\section{Hypothesis Validation}

\section{Assumptions of Multiple Linear Regression}

In order to answer the research questions proposed in the present and validate the research hypotheses, three linear regressions were performed, of which two multiple and one simple. But first, several key assumptions had to be confirmed.

First, multiple linear regression requires the relationship between the independent and dependent variables to be linear. The linearity assumption can best be tested with scatterplots. Looking at the scatterplots, we could confirm that the relationship between the independent and dependent variables could be modelled by a straight line, suggesting that the relationship between these variables is linear.

Second, the multiple linear regression analysis requires that the errors between observed and predicted values should be normally distributed. This assumption may be verified with a goodness of fit test. In accordance, the KolmogorovSmirnov test (K-S) was used to test the normality of the variables. Analyzing the results obtained by the test and considering the $\mathrm{p}$-value $<0.05$ for all variables in the study, we have observed that they do not follow a normal distribution and the null hypothesis is rejected (H0: the variable follows a normal distribution; H1: the variable does not follow a normal distribution). However, using the Theorem of Central Limit (TCL), which states that in large samples $(\mathrm{N}=242>30)$ we can consider that they follow a normal distribution, thus it is feasible to carry out regressions.

Third, multiple linear regression assumes that there is no multicollinearity in the data. Multicollinearity occurs when the independent variables are too highly correlated with each other. This assumption was tested using Variance Inflation Factor (VIF) values, through which we were able to verify that all the VIF scores are close to 1 and never above 10 , and the tolerance scores are above 0,2 , thus we were able to validate this assumption.

Then, through the Durbin-Watson test (d) we could verify the assumption of independence of errors or the absence of autocorrelation. In this case, we were able to confirm that the errors are not autocorrelated, as all the values were close to $2(d 1=2.060 ; d 2=2.004 ; d 3=1.995)$ validating the assumptions.

The last assumption of multiple linear regression is homoscedasticity. This assumption states that the variances of error are similar across the values of the independent variables. A scatterplot of residuals versus predicted values is good way to check for homoscedasticity and as there is no clear pattern in the distribution, we can confirm that this assumption was met. 


\section{Relationship between Consumer Perceptions and Online Trust}

In order to answer the first research question and to validate the research hypotheses H1a, H1b, H1c and H1d, a multiple regression was performed. This regression had the influencer trust as a dependent variable and as independent variables: similarity to the influencer, influencer credibility, brand credibility and credibility of the message.

The model of the first multiple regression, through the analysis of the $F$ test $(F(4)=51.508, p$-value $=0.000)$, demonstrates significance and allows to reject the null hypothesis, thus confirming the validity. While considering the adjusted coefficient of determination, it is possible to verify that the independent variables chosen for the study (similarity to the influencer, influencer credibility, brand credibility and credibility of the message) explain $45.6 \%$ of the total variation in consumer trust in relation to digital influencers of fashion. Regarding the value obtained by the standard error of the estimate ( $\mathrm{S}=0.62595$ ), which corresponds to the standard deviation of the predicted values of the dependent variable (influencer trust) around the estimated regression line, being a low value means that there is a good fit between observed and estimated values. Continuing with the impact that each independent variable has in the confidence, we can verify that the similarity with the influencer $(b=0.120 ; t=2.191 ; p$-value $=0.029)$, the influencer credibility $(b=0.195 ; t=3.122 ; p$-value $=0.002)$, the brand credibility $(b=0.416 ; t=6.524 ; p$-value $=0.000)$ and the credibility of the message $(b=0.122 ; t=2.345 ; p$-value $=0.200)$ have a statistically significant impact on influencer trust. In this sense, hypotheses H1a, H1b, H1c and H1d are confirmed.

\section{Relationship between Consumer Perceptions (beliefs) and Purchase Intention}

In order to validate the research hypotheses $\mathrm{H} 2 \mathrm{a}, \mathrm{H} 2 \mathrm{~b}, \mathrm{H} 2 \mathrm{c}$ and $\mathrm{H} 2 \mathrm{~d}$, a multiple linear regression was performed. The dependent variable of this regression is the purchase intention and the dependent variables are influencer similarity, influencer credibility, brand credibility and message credibility.

With regard to the results obtained through the analysis of the coefficient of determination (adjusted), it is possible to affirm that $32.5 \%$ of the total variation of the purchasing intention is explained by the independent variables. With the values obtained through the $\mathrm{F}$ test $(\mathrm{F}(4)=30.805$, $\mathrm{p}$-value $=0.000)$, it is possible to validate the model, thus rejecting the null hypothesis of this test. Regarding the value obtained by the standard error $(\mathrm{S}=0.677824)$, it is confirmed again that there is a good fit between the sample and the values estimated by the model. Regarding the impact that the variables have on the purchase intention, it can be seen that the influencer similarity $(b=0.257 ; \mathrm{t}=4.224$; $\mathrm{p}$-value $=$ $0.000)$, the influencer credibility $(b=0.154 ; \mathrm{t}=2.217 ; \mathrm{p}$-value $=0.028)$, the brand credibility $(\mathrm{b}=0.227 ; \mathrm{t}=3.188 ; \mathrm{p}$ value $=0.002)$ and the credibility of the message $(b=0.124 ; t=2.151 ; p$-value $=0.032)$ have a statistically significant impact on purchase intent. Thus, it can be said that hypotheses $\mathrm{H} 2 \mathrm{a}, \mathrm{H} 2 \mathrm{~b}, \mathrm{H} 2 \mathrm{c}$ and $\mathrm{H} 2 \mathrm{~d}$ are confirmed.

\section{Relationship between Influencer Trust and Purchase Intention}

To validate the hypothesis $\mathrm{H} 3$ a simple linear regression was applied, where the influencer trust is an independent variable and the dependent variable is purchase intention. Observing the value of the coefficient of determination (adjusted), we can conclude that $28.9 \%$ of the total variation of purchase intention is explained by trust. According to the results obtained in the $F$ test $(F(1)=98.772 p$ value $=0.000)$, it can be said that there is significance and eliminate the null hypothesis. Regarding the standard error of the estimate $(S=0.69629)$ which is, again, low, and means that there is a good fit between the observed values of the sample and the values estimated by the model. Finally, regarding the impact that influencer trust has on the purchase intention, we can say that trust $(\mathrm{b}=0.540 ; \mathrm{t}=9,938$; $\mathrm{p}$-value $=$ 0.000) has a statistically significant impact on the intention to purchase, thus hypothesis $\mathrm{H} 3$ is supported.

\section{DISCUSSION OF FINDINGS}

According to the results obtained in the investigation, it should be noted that all tested hypotheses are found to be statistically significant in explaining influencer trust and purchase intention. First, we tried to verify the possible antecedents of influencer trust and concluded that the trust customers have in the influencer is affected by their similarity with the influencer, influencer credibility, brand credibility and message credibility. Additionally, it was possible to conclude that the brand credibility is the antecedent that most influences trust, while the credibility of the influencer and the credibility of the message, and the least influencing in the resemblance to the source. Then we tested the antecedents in relation with purchase intent and also found the existence of a relationship between the 
variables. In this case, it was observed that the brand's credibility was again the antecedent that influences more the purchase intention. Interestingly, the similarity with the influencer ranked last.

Taking into account the items that constitute each of the variables, for the variable 'similarity to the influencer', it is possible to verify that the respondents value more the item: "My preferences are similar to those of influencers" (average of 3.1) and the least valued is "I'm similar to fashion influencers" (average of 2.43).

As for the influencer credibility, the item that was found to have the most positive impact was "They remain well informed in relation to industry trends" (average 4.06), and the one with the least impact was "They have professional experience in the sector" (average 2.96).

Then, as regarding the credibility of the brand, the comparison of the means of the different items, allows to conclude that the respondents give more value to the item "The communication activities of brands with influencers are credible" (average of 3.33), and the item they value least is "The communication activities between brands and influencers are honest" (average of 3.13).

Regarding the credibility of the message, comparing the averages of all items inherent, it is possible to conclude that respondents value more "Attractive descriptions add exclusivity to the posts of the profiles of the digital influencers" (average of 4.07) and the least valued item was "Captivating descriptions make Instagram posts more credible" (average of 3.91). Still regarding this last index, the credibility of the message, it is important to mention that it presents itself as having the most average high.

Subsequently, analyzing the relationship between influencer trust and consumer purchase intention validated that trust positively influences the consumer purchase intention, confirming the $\mathrm{H} 3$ research hypothesis. As for the influencer trust, the comparison of means of the different items of the measurement scale used, allows us to verify that the averages are all very close, and what the respondents value most is "I believe influencers are reliable" and the least valued item is "I believe that influencers don't just care about them own".

Regarding the items related to the purchase intention, we can confirm that the item that respondents value most is "I consider buying an article advertised by an influencer, in case I need that article" (average of 3.87) and the item with the least value is "I don't hesitate to buy an article advertised by an influencer" (average of 2.07).

\section{IMPLICATIONS FOR RESEARCH/PRACTICE}

From the academic point of view, this paper contributed to the existing literature regarding consumer behavior towards digital influencers and therefore bringing new evidence into the underlying theories. Evidently, this investigation allowed a better understanding of the perceptions that consumers have about digital influencers, which is still an area not extensively investigated. The results contributed to the knowledge of relationships between variables that had not yet been studied together, such as similarity to the influencer, influencer credibility, credibility of the message and credibility of the brand. It should also be noted that the credibility of the message, according to the data obtained, presents itself as the one that plays a more relevant relationship with trust and purchase intention what also confirms the assumptions of self-congruence and social identity theory. The model's adequacy and reliability were verified.

As it comes to business contributions, while considering the emancipation of the Instagram and other social media, the analysis of relations established in this investigation is of enormous importance, as the understanding of the perception of consumers in relation to influencers can guide the future influencer choice. The present study has also emphasized that the inclusion of influencers in the marketing will be beneficial for fashion professionals in order to establish more consistent relationships with consumers. Finally, given the scarcity of studies in this area in the Portuguese context, this study contributed to marketeers who increasingly invest in this marketing tactic.

\section{STUDY LIMITATIONS}

The present study also has some limitations. A first limitation concerns the method used, in this case the single method, using only a quantitative analysis. The use of a non-probabilistic convenience sample, that is, makes the results obtained not generalizable to the whole population. Also, it is important to notice that most of the sample under study 
are young, single women coming from different regions in Portugal. Another limitation also arises as it comes to the sector choice. Indeed, the fashion sector is one of the most presence of the influencers, but other sectors, such as the beauty sector, could be also considered. Future tests using structural equation modelling would be recommended. Alongside this analysis, a qualitative analysis could be also carried out to conduct in-depth interviews with fashion influencers in a way to understand how they convey confidence to their followers.

\section{CONCLUSIONS}

The research objectives of this study were achieved: a framework of the relationship between customer perceptions that determine the influencer trust and intention to buy was presented, tested, and validated using a sample of Portuguese consumers. In a way to propose the framework a set of underlying theoretical assumptions was considered and found its confirmation in a new empirical context.

Considering the research problem, which involved exploring consumer perceptions of digital fashion influencers and their impact on purchase intention, it can be affirmed that the objective of this study was accomplished. There is indeed a relation between the consumer perceptions of influencers and the trust in influencer which relates to the previous findings by Hoonsopon and Puriwat (2016). Most importantly, brand credibility appears to be the strongest factor in this relationship. This confirms the previous studies testing the weight of brand awareness on customer confidence (Lou \& Yuan, 2018). It also confirms the earlier research (e.g. Hoonsopon \& Puriwat, 2016) on the importance of information, from both private and public groups, that can influence shoppers to purchase products.

As it comes to the relationship between consumer perceptions and the intention to purchase it can be concluded that the similarity with the influencer, influencer credibility, credibility of the brand and credibility of the message establish a positive relationship with the intention to purchase. Again, it turns out that brand credibility is the antecedent that most influences this relationship.

Third, the question arose as to the existence of a relationship of trust in influencers and the intention to purchase. This research has shown that trust positively affects purchase intention.

\section{REFERENCES}

Abrams, D. E., \& Hogg, M. A. (1990). Social identity theory: Constructive and critical advances. Springer-Verlag Publishing.

Ahmad, I. (2018). The Influencer Marketing Revolution. Social Media Today, February 16, https:// www.socialmediatoday.com/news/the-influencer-market- ing-revolution-infographic/517146/.

Ashforth, B. E., \& Mael, F. (1989). Social identity theory and the organization. Academy of Management Review, 14(1), 20-39.

Asur, S., Huberman, B. A., Szabo, G., \& Wang, C. (2011). Trends in Social Media: Persistence and Decay. SSRN Electronic Journal, 1-8.

Bro, S. (2017). Influencer Marketing Disclosures. Orange County Business Journal, 40(47), 49.

Casaló, L. V., Flavián, C., \& Ibáñez-Sánchez, S. (2018). Influencers on Instagram: Antecedents and consequences of opinion leadership. Journal of Business Research, 1-10.

Chai, S., Das, S., \& Rao, H. R. (2011). Factors Affecting Bloggers' Knowledge Sharing: An Investigation Across Gender. Journal of Management Information Systems, 28(3), 309-342.

Chai, S., \& Kim, M. (2010). What makes bloggers share knowledge? An investigation on the role of trust. International Journal of Information Management, 30(5), 408-415.

Chaturvedi, S., \& Barbar, R. (2014). Impact of Social Media on Self-Esteem. European Scientific Journal, 2(2), 107114.

Chuchinprakarn, S. (2005). Application of the theory of reasoned action to on-line shopping. Knowledge Center Epaper Bangkok University, 1-7.

Cosenza, T. R., Solomon, M. R., \& Kwon, W. (2014). Credibility in the blogosphere: A study of measurement and influence of wine blogs as an information source. Journal of Consumer Behaviour, 14(2), 71-91.

Corritore, C. L., Kracher, B., \& Wiedenbeck, S. (2003). On-line trust: concepts, evolving themes, a model. International Journal of Human-Computer Studies, 58(6), 737-758. 
Cosenza, T. R., Solomon, M. R., \& Kwon, W. (2014). Credibility in the blogosphere: A study of measurement and influence of wine blogs as an information source. Journal of Consumer Behaviour, 14(2), 71-91.

Costa, I. P. \& Alturas, B. (2018). Líderes de Opinião Digital portugueses, e o seu impacto, na promoção de produtos, serviços e eventos nas redes sociais. In 13a Ed. Iberian Conference on Information Systems and Technologies.

Curiel, C. P., \& Ferreira, L. C. (2017). Comunicación y social media en las empresas de moda. Ciudadania Digital y Open Data Acess, 18, 226-258.

Erdem, T., Swait, J., \& Valenzuela, A. (2006). Brands as Signals: A Cross-Country Validation Study. Journal of Marketing, 14(2), 71-91.

Erdogmus, E., \& Çiçek, M. (2012). The Impact of Social Media Marketing on Brand Loyalty. Procedia - Social and Behavioral Sciences, 58, 1353-1360.

Esch, P., Arli, D., Castner, J., Talukdar, N., Northey, G. (2018). Consumer attitudes towards bloggers and paid blog advertisements: what's new?. Marketing Intelligence \& Planning, 36(7), 778-793.

Freberg, K., Graham, K., McGaughey, K., \& Freberg, L. A. (2011). Who are the social media influencers? A study of public perceptions of personality. Public Relations Review, 37(1), 90-92.

Hill, M. M., Hill, A. (2012). Investigação por Questionário (2nd ed.). Lisboa: Edições Sílabo.

Ho, H.Y., \& Chien, P.H.C. (2010). Influence of message trust in online word-of-mouth on consumer behavior - by The example of food blog. International Conference on Electronics and Information Engineering, 395-399.

Hoonsopon, D., \& Puriwat, W. (2016). The effect of reference groups on purchase intention: Evidence in distinct types of shoppers and product involvement. Australasian Marketing Journal (AMJ), 24(2), 157-164.

Hu, Y., Manikonda, L., \& Kambhampati, S. (2014). What we instagram: a first analysis of instagram photo content and user types. In Proceedings of AAAI International Conference on Web and Social Media., 595-598.

Fay Group (2016). The Power of Influencers. Quantified. http://go2.experticity.com/rs/288-AZS731/images/Power\%20of\%20Influence\%20Quantified.pdf?_ga=1.132711370.57888 514.1433263104

Kim, A. J., \& Ko, E. (2012). Do social media marketing activities enhance customer equity? An empirical study of luxury fashion brand. Journal of Business Research, 65(10), 1480-1486.

Lee, K.T., \& Koo, D.M. (2012). Effects of attribute and valence of e-WOM on message adoption: Moderating roles of subjective knowledge and regulatory focus. Computers in Human Behavior, 28(5), 1974-1984.

Lindh, C., \& Lisichkova, N. (2017). Rationality versus emotionality among online shoppers: The mediating role of experts as enhancing influencer effect on purchasing intent. Journal of Customer Behaviour, 16(4), 333-351.

Liu, F., Li, J., Mizerski, D., \& Soh, H. (2012). Self-congruity, brand attitude, and brand loyalty: a study on luxury brands. European Journal of Marketing, 46(7/8).

Lu, L.C. Chang, W.P., \& Chang, H.H. (2014). Consumer attitudes toward blogger's sponsored recommendations and purchase intention: The effect of sponsorship type, product type, and brand awareness. Computers in Human Behavior, 34, 258-266.

Malhotra, N. K., \& Birks, D. F. (2006). Marketing Research: An Applied Approach (3 ${ }^{\text {rd }}$ ed.). England: Prentice Hall.

Marktest Group (2017). Instagram foi a rede social que mais cresceu em Portugal [Em linha]. Disponível em: https://www.marktest.com/wap/a/n/id 2303.aspx [Acesso em: 2019/10/5].

Montano, D. E., \& Kasprzyk, D. (2015). Theory of reasoned action, theory of planned behavior, and the integrated behavioral model. Health behavior: Theory, research and practice, 70(4), 231.

Moon, E., \& Han, S. (2011). A qualitative method to find influencers using similaritybased approach in the blogosphere. International Journal of Social Computing and Cyber-Physical Systems, 1(1), 56.

Moorman, C., Deshpande, R., \& Zaltman, G. (1993). Factors affecting trust in market research relationships. Journal of Marketing, 57(1), 81-101.

Morgan, R. M., \& Hunt, S. D. (1994). The commitment-trust theory of relationship marketing. Journal of Marketing, 58(3), 20-38.

Oluremi Oke, A., Kamolshotiros, P., Yewande Popoola, O., Akintunde Ajagbe, M., \& Joshua Olujobi, O. (2016). Consumer behavior towards decision making and loyalty to particular brands. International Review of Management and Marketing Asia International Conference, 6(S4), 43-52.

Oke, A., Kamolshotiros, P., Yewande Popoola, O., Akintunde Ajagbe, M., \& Olujobi, J. O. (2016). Consumer behavior towards decision making and loyalty to particular brands. International Review of Management and Marketing - Asia International Conference, 6(S4), 43-52.

Pallant, J. (2016). SPSS survival manual: A step by step guide to data analysis using SPSS (6th ed.). London: McGrawHill Education. 
Soh, H., Reid, L.N, \& Whitehill King, K. (2009). Measuring Trust in Advertising. Journal of Advertising, 38(2), 83104.

Solomon, M. (2009). Consumer Behavior: Buying, Having, and Being (8th ed.). New York: Pearson.

Sounders, M., Lewis, P., \& Thornhill, A. (2016). Research Methods for Business Students (7th ed.). Harlow, England: Pearson.

Spry, A., Pappu, R., \& Cornwell, B.T. (2011). Celebrity endorsement, brand credibility and brand equity. European Journal of Marketing, 45(6), 882-909.

Sudha, M., \& Sheena, K. (2017). Impact of Influencers in Consumer Decision Process: the Fashion Industry. Journal of Indian Management, 14(3), 14-30.

Taba, K. S., The Use of Cronbach's Alpha When Developing and Reporting Research Instruments in Science Education. Research in Science Education, 48(6), 1273- 1296.

Tarik, Z., \& Adnan, S. (2018). Online vs Traditional: Marketing Challenge in the Telecom Market in Bosnia and Herzegovia. Journal of Economics and Business, 16(1), 45-57.

Uzunoğlu, E., \& Misci, K.S. (2014). Brand communication through digital influencers: Leveraging blogger engagement. International Journal of Information Management, 34(5), 592-602.

Vázquez-Casielles, R., Suárez-Álvarez, L., \& del Río-Lanza, A.-B. (2013). The Word of Mouth Dynamic: How Positive (and Negative) WOM Drives Purchase Probability. Journal of Advertising Research, 53(1), 43-60.

Veirman, M., Cauberghe, V., \& Hudders, L. (2017). Marketing through Instagram influencers: the impact of number of followers and product divergence on brand attitude. International Journal of Advertising, 36(5), 798-828.

Voramontri, D., Klieb, L., \& Walker, G. H. (2018). Impact of social media on consumer behaviour. International Journal Information and Decision Sciences, 10, 1-25.

Westbrook, R. A., \& Oliver, R. L. (1991). The Dimensionality of Consumption Emotion Patterns and Consumer Satisfaction. Journal of Consumer Research, 18(1), 84-91.

Xu, X., \& Pratt, S. (2018). Social media influencers as endorsers to promote travel destinations: an application of selfcongruence theory to the Chinese Generation Y. Journal of Travel \& Tourism Marketing, 35(7), 958-972. 